\title{
Corporate real estate strategies and financial performance of companies
}

\begin{abstract}
This study analyzes the relationship between Corporate Real Estate (CRE) strategy and the financial performance of major companies in the UK for two time periods, 1998 and 2003. The identification of specific CRE strategies is based on the seminal work of Nourse and Roulac (1993). The results indicate that more than $75 \%$ of the companies examined had a CRE strategy that could be mapped to the Nourse and Roulac framework and that certain CRE strategies made a contribution in enhancing the financial performance of companies. The relationship was stronger for companies in 2003 than for 1998. This was tested for both share price and profit margin as the dependent variable. This study concludes that CRE strategy can make a limited contribution to company financial performance.
\end{abstract}

Keyword: Corporate real estate; Financial performance; UK companies; Multivariate modelling 